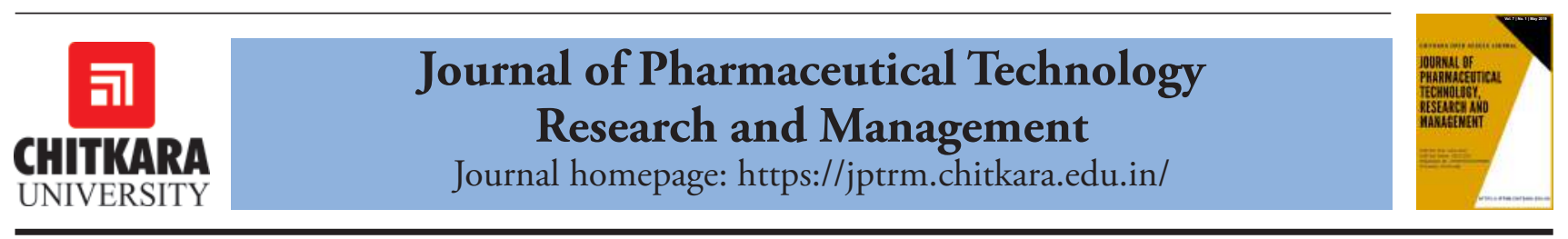

\title{
A Validated High Performance Thin Layer Chromatographic Method for Simultaneous Estimation of Berberine Chloride and Guggulsterone $Z$ in Herbal Formulation
}

\author{
Vijaykumar K. Parmar ${ }^{1, *}$, Deepika Mohanta ${ }^{2}$ and Harsh Shah ${ }^{2}$ \\ ${ }^{1}$ Department of Pharmaceutical Sciences, Sardar Patel University, VallabhVidyanagar - 388 120, Gujarat, INDIA \\ ${ }^{2}$ Ramanbhai Patel College of Pharmacy, Charotar University of Science and Technology, Changa - 388421, Gujarat, INDIA
}

*Email:vijaykparmar@gmail.com

\section{ARTICLE INFORMATION}

Received: Nov. 07, 2018

Revised: January 09, 2019

Accepted: Feb. 08, 2019

Published online: May 10, 2019

Keywords:

Berberine chloride; Guggulsterone Z; HPTLC; Herbal formulation

DOI: https://doi.org/10.15415/jptrm.2019.71002

\begin{abstract}
A simple, precise, and robust high-performance thin layer chromatography (HPTLC) method was developed and validated for the determination of berberine chloride and guggulsterone $\mathrm{Z}$ in herbal formulation.Chromatographic separation was achieved on aluminium plates precoated with silica gel G60F254 as the stationary phase and toluene-acetonitrile-formic acid (5:3:0.5 v/v/v) as the mobile phase. Densitometric evaluation was carried out at $264 \mathrm{~nm}$. The present method was validated according to ICH guidelines. The $\mathrm{Rf}$ value of berberine chloride and guggulsterone $\mathrm{Z}$ was found to be $0.40 \pm 0.02$ and $0.68 \pm 0.02$, respectively. The response in terms of peak area were found to be linear over the concentration range of 100-500 ng/spot for berberine chloride and 200-1000 ng/spot for guggulsterone $\mathrm{Z}$ with regression coefficient value greater than 0.995 for both the phytoconstituents. The method was validated by determining its accuracy, precision, robustness, specificity and system suitability. The method was found to be accurate, precise and robust to carry out the simulataneous estimation of berberine chloride and guggulsterone $Z$. The developed method was successfully applied for the simultaneous estimation of berberine chloride and guggulsterone $\mathrm{Z}$ in herbal formulation.
\end{abstract}

\section{Introduction}

Hemorrhoids, also known as piles, are swollen veins located around the anus or in the lower rectum. It can either be internal or external. The symptoms of hemorrhoids include extreme itching around the anus, irritation and pain around the anus, itchy or painful fecal leakage, painful bowel movement, blood on tissue after having a bowel movement. Commiphora wightii (Guggulu) is known for its active ingredients guggulsterones (GE\& GZ). It has astringent, antiseptic with anti-inflammatory and demulcent properties that helps to reduce the pain and inflammation. Berberisaristata (Daruharidra) is known for its isoquinoline alkaloid, berberine (BER). It is found to have antibacterial, anti-inflammatory and laxative properties and is useful in hemorrhoids [4]. Combination of these drugs are used in the treatment of hemorrhoids. Literature review revealed that UV, HPLC, HPTLC methods have been reported for the estimation of individual phytoconstituents, BER and GZ in crude and herbal formulation \& LC-MS, LC-MS-MS have been reported for the estimation in biological fluid $[2,3]$. Any method has not been reported for the simultaneous estimation of both the phytoconstituents from herbal formulation. Thus, it was a thought of interest to develop and validate analytical method for simultaneous estimation of BER and GZ.

\section{Experimental}

\subsection{Materials}

Berberine chloride $(97.6 \%)$ was purchased from SigmaAldrich, Bangalore, India and guggulsterone $\mathrm{Z}$ was purchased from Natural Remedies Pvt. Ltd, Bangalore, India. Formulation containing berberisaristata $(64 \mathrm{mg})$ and guggul (260 mg), Pilex from Himalaya Herbals, Gujarat was procured from local market. Methanol, toluene, acetonitrile and formic acid were procured from LobaChemie, Mumbai, India.

\subsection{Instrumentation}

Precoated silica gel $\mathrm{G} 60 \mathrm{~F}_{254}$ on aluminum sheet used as stationary phase was procured from Merck Millipore, India and CAMAG (Muttenz, Switzerland) HPTLC systemwas used for spotting, development and scanning of TLC plate.

\subsection{Preparation of Standard solutions}

Berberine chloride $(10 \mathrm{mg})$ was accurately weighed and transferred to $10 \mathrm{ml}$ capacity volumetric flask and volume was made up to mark with methanol. Aliquot $(1 \mathrm{~mL})$ was diluted up to $10 \mathrm{~mL}$ with methanol in a volumetric 
flask to obtain BER stock solution containing $100 \mu \mathrm{g} /$ $\mathrm{mL}$ of berberine chloride. Guggulsterone $\mathrm{Z}(5 \mathrm{mg})$ was accurately weighed and transferred to $50 \mathrm{~mL}$ capacity volumetric flask and volume was made up to mark with methanol to obtain GZ stock solution containing $100 \mu \mathrm{g} /$ $\mathrm{mL}$ stock solution.

\subsection{Preparation of Sample solution}

Twenty tablets were weighed and powdered. 5 gram tablet powder was weighed. It was extracted thrice with $25 \mathrm{~mL}$ petroleum ether. Residue was collected and again extracted with $25 \mathrm{~mL}$ chloroform thrice to obtain GZ. The chloroform layer was combined, reduced to $20 \mathrm{~mL}$ and transferred in to $25 \mathrm{~mL}$ volumetric flask; volume made up to mark with chloroform (solution A). Residue was collected and again extracted with $25 \mathrm{~mL}$ methanol thrice to obtain BER. Methanol layer was combined. $5 \mathrm{~mL}$ of $1 \%$ $\mathrm{HCl}$ was added to it, reduced to $20 \mathrm{~mL}$ and transferred to $25 \mathrm{~mL}$ volumetric flask; volume made up to mark with methanol (solution B).

\subsection{Chromatographic Separation}

Appropriate volumes of standard solutions or sample solutions were spotted on the TLC plate at constant application rate of $159 \mathrm{~nL} / \mathrm{sec}$ in the form of bands with bandlength of $8 \mathrm{~mm}$. The chromatogram was developed in ascending mode in a twin-trough chamber previously saturated with the mobile phase (toluene-acetonitrile-formic acid, 5: 3: $0.5 \mathrm{v} / \mathrm{v} / \mathrm{v}$ ) for $20 \mathrm{~min}$. The chromatogram was allowed to migrate to a distance of $8 \mathrm{~cm}$. The developed TLC plate was dried and densitometric scanning was performed at $264 \mathrm{~nm}$ on Linomat Scanner IV in the absorbancereflectance mode using a slit-dimension of $6.00 \times 0.20 \mathrm{~mm}$ and a scanning speed of $20 \mathrm{~mm} / \mathrm{s}$.

\subsection{Calibration Curve for BER and GZ}

Aliquots of 1, 2, 3, 4 and $5 \mu \mathrm{L}$ of BER $(100 \mu \mathrm{g} / \mathrm{ml}$; corresponding to $100,200,300,400$ and $500 \mathrm{ng} / \mathrm{spot}$ of BER) and aliquots of 2, 4, 6, 8, $10 \mu \mathrm{L}$ of GZ $(100 \mu \mathrm{g} / \mathrm{ml}$; corresponding to $200,400,600,800$ and $1000 \mathrm{ng} / \mathrm{spot}$ of GZ) were overspotted on TLC plate and analyzed as described under chromatographic separation. Calibration curves for BER and GZ were prepared by plotting peak area of BER and GZ against their respective concentration.

\subsection{Validation of HPTLC method}

The developed method was validated as per ICH Q2(R1) guideline.

\subsection{Specificity}

The spots of BER and GZ were confirmed by comparing the $\mathrm{R}_{f}$ and absorbance-reflectance spectrum of the sample with those of the standard. The peak purity of BER and GZ were assessed by comparing the spectra at three different levels, i.e., peak start $(\mathrm{s})$, peak apex $(\mathrm{m})$ and peak end (e) positions and correlations between them $\left[\mathrm{r}^{2}(\mathrm{~s}, \mathrm{~m})\right.$ and $\left.\mathrm{r}^{2}(\mathrm{~m}, \mathrm{e})\right]$ were considered for the determination of peak purity.

\subsection{Linearity}

The linearity of BER and GZ were assessed by analysis of five different concentrations in the range of 100-500 ng/ spot for BER and 200-1000 ng/spot for GZ in terms of correlation co-efficient values.

\subsection{Precision.}

\subsubsection{Repeatability of Sample Application}

BER standard solution containing $300 \mathrm{ng} / \mathrm{spot}$ of BER and $6 \mu \mathrm{l}$ of GZ containing $600 \mathrm{ng} / \mathrm{spot}$ of GZ (3 $\mu \mathrm{l})$ was spotted seven times on TLC plate. The plate was developed, dried and photometrically analyzed as described under chromatographic separation. The areas of seven spots were measured and relative standard deviation (\%RSD) was calculated.

\subsubsection{Repeatability of measurement of peak area and $\boldsymbol{R}_{f}$}

BER standard solution containing $300 \mathrm{ng} / \mathrm{spot}$ of BER and $6 \mu \mathrm{l}$ of GZ containing $600 \mathrm{ng} / \mathrm{spot}$ of GZ(3 $\mu \mathrm{l})$ was spotted seven times on TLC plate. The plate was developed, dried and photometrically analyzed as described under chromatographic separation. Area and $\mathrm{R}_{f}$ of spot was measured seven times without changing the position of plate and \%RSD of obtained data was calculated.

\subsection{Reproducibility}

\subsubsection{Intraday reproducibility}

Variation of results within same day is called as intraday variation. It (\%RSD) was determined by spotting three middle concentrations $(2,3,4 \mu \mathrm{l}$ of BER and 2, 4, $6 \mu \mathrm{l}$ of GZ) of calibration curve three times on the same day on TLC plate.

\subsubsection{Interday reproducibility}

It (\%RSD) was determined by spotting three middle concentrations $(2,3,4 \mu \mathrm{l}$ of BER and 2, 4, $6 \mu \mathrm{l}$ of GZ) of calibration curve for three times on 3 different days on TLC plate. 


\subsection{Limit of Detection (LOD) and Limit of Quantification (LOQ)}

The LOD and LOQ were separately determined at a signal-to-noise ratio of 3 and 10. LOD and LOQ were experimentally verified by diluting known concentrations of BER and GZ until the average responses were 3 or 10 times of the standard deviation of the responses for 6 replicate determinations.

\subsection{Accuracy}

Accuracy (\% recovery) was determined by analysis of previously analyzed sample spiked with the standard solution of BER and GZ at three levels (80, 100, $120 \%$ ). Three replicates from each sample were performed and mean recovery (\%) was calculated.

\subsection{Robustness}

Robustness testing was carried out using experimental design approach (Design Expert 9). Plackett-Burman design for testing seven factors was selected for robustness testing. Table 1 depicts the factors selected and their levels for robustness testing of the proposed method. The peak area and \% recovery of BER and GZ were observed at each experiment

Table 1. Linearity data of BER and GZ $(n=6)$ designed. The experiments designed were repeated three times in random order. The significance of factors effects was determined graphically by means of Pareto chart.

\subsection{Analysis of Sample Solutions}

Sample solution $(10 \mu \mathrm{l})$ was spotted on the TLC plate and analyzed as described under chromatographic condition. The experiment was repeated 3 times. The \% content was calculated by fitting peak area values into calibration equation of BER and GZ.

\section{Results and Discussion}

\subsection{Method Optimization}

For the estimation of BER and GZ, different solvent systems in varying ratios of toluene, ethyl acetate, water, acetonitrile, formic acid were tried and photometrically scanned at $264 \mathrm{~nm}$ (iso-absorptive point of BER and GZ). Finally, suitable separation and symmetric peak shape were achieved using a mobile phase system consisting of toluene-acetonitrile-formic acid (5:3: $0.5 \mathrm{v} / \mathrm{v} / \mathrm{v})$ previously saturated for $20 \mathrm{~min}$ at $25^{\circ} \mathrm{C}$. The $\mathrm{R}_{f}$ value of BER was found to be $0.40 \pm 0.02$ and $0.68 \pm 0.02$ (Fig. 1 and 2).

\begin{tabular}{llllll}
\hline BER & & GZ & \\
\hline $\begin{array}{l}\text { Concentration } \\
\text { (ng/spot) }\end{array}$ & $\begin{array}{l}\text { Peak Area } \\
\text { Mean } \pm \text { SD }\end{array}$ & \% RSD & $\begin{array}{l}\text { Concentration } \\
\text { (ng/spot) }\end{array}$ & $\begin{array}{l}\text { Peak Area } \\
\text { Mean } \pm \text { SD }\end{array}$ & \% RSD \\
\hline 100 & $1848.26 \pm 35.73$ & 1.93 & 200 & $3511.66 \pm 65.47$ & 1.86 \\
200 & $2771.18 \pm 29.7$ & 1.07 & 400 & $5590.72 \pm 111.49$ & 1.98 \\
300 & $3590.76 \pm 45.87$ & 1.27 & 600 & $7216.78 \pm 168.25$ & 1.91 \\
400 & $4866.95 \pm 61.88$ & 1.27 & 800 & $9615.59 \pm 202.14$ & 1.75 \\
500 & $5707.95 \pm 60.99$ & 1.06 & 1000 & $11300.86 \pm 227.34$ & 1.91 \\
\hline
\end{tabular}

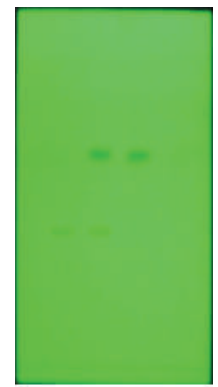

123

Figure 1. Developed TLC plate of showing separation of BER and GZ at Rf value of $0.40 \pm 0.02$ and $0.68 \pm 0.02$, repectively (Track 1 - Standard solution of BER, Track 2 - Mixture of BER and GZ, Track 3 - Standard solution of GZ)

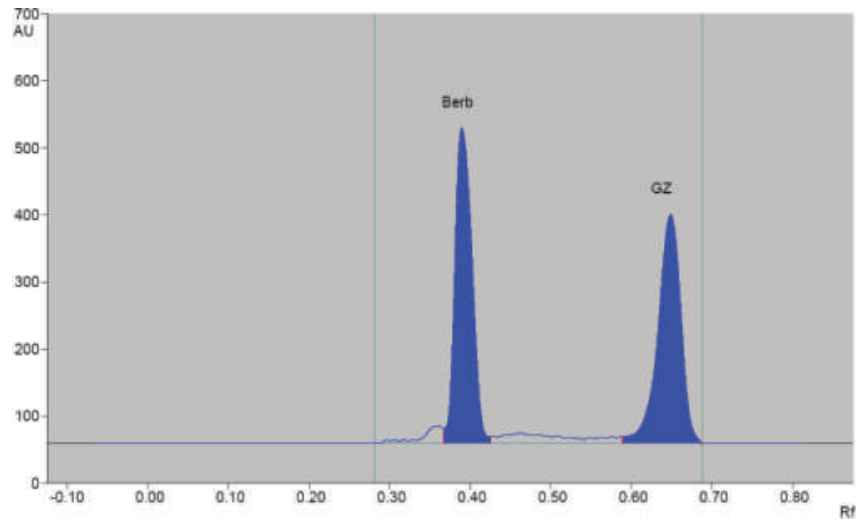

Figure 2. Chromatogram of $B E R \mathrm{Rf}=0.40 \pm 0.02$ and $\mathrm{GZ} \mathrm{Rf}=$ $0.68 \pm 0.02$ 


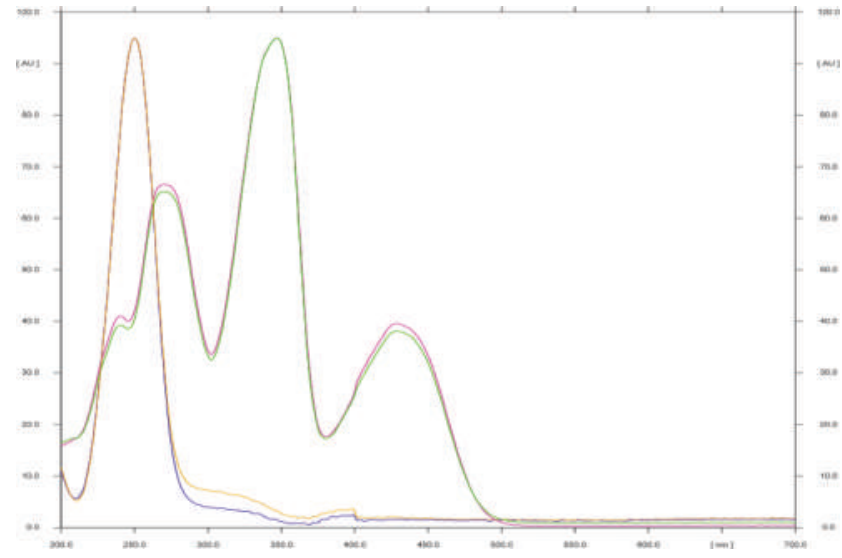

Figure 3. Overlay spectra of BER and GZ standard and sample

\subsection{Validation of HPTLC Method}

\subsubsection{Specificity}

Comparison of chromatograms of standard solution and sample solution from formulation showed identical $\mathrm{R}_{f}$ values i.e. $0.40 \pm 0.02$ for $\mathrm{BER}$ and $0.68 \pm 0.2$ for GZ. Comparison of the spectra scanned at peak start $(\mathrm{S})$, middle (M) and end (E) showed high degree of correlation (above 0.990). This confirmed the purity of the corresponding spots. Also, the spectrum of individual sample was compared with the spectrum of standard BER and GZ. The correlation obtained was 0.9996 for BER and 0.9992 for GZ (Fig. 3), this confirmed the identity of spots.

\subsection{Linearity}

BER showed good correlation coefficient in the concentration range of 100-500 ng/spot and GZ in the concentration range of 200-1000 ng/spot. The linear regression analysis obtained by plotting the peak areas of analyteversus concentration showed good correlation coefficients (correlation coefficient greater than 0.995 ). The overlain linearity chromatogram is shown in Fig.4. The regression equation for BER and GZ was found to be $\mathrm{y}=9.8151 \mathrm{x}+812.48$ and $\mathrm{y}=9.8016 \mathrm{x}+$ 1566.1, respectively.

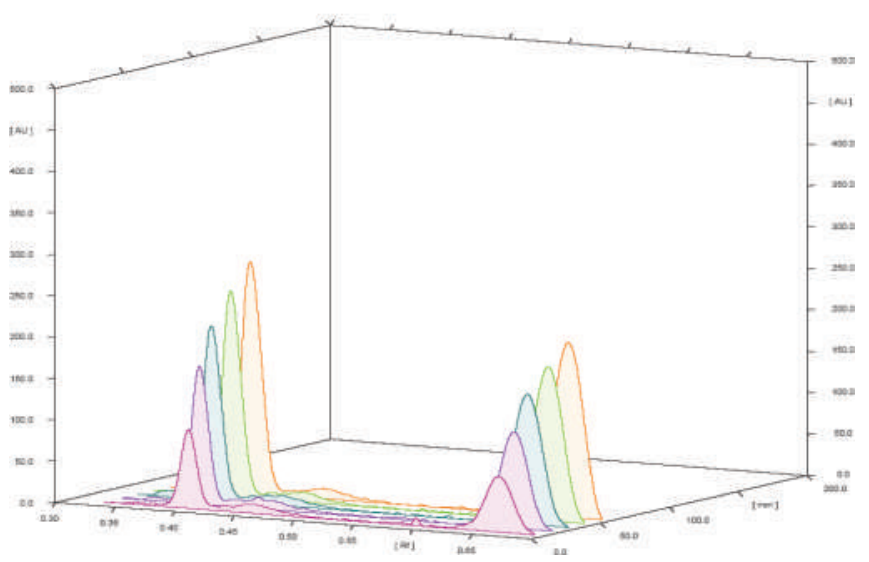

Figure 4. Overlain linearity chromatogram of BER and GZ

\subsection{Precision}

The \% RSD for repeatability of peak area measurement of BER and GZ were 0.38 and 0.31 , respectively (Table 2) and repeatability of sample application were 0.32 and 0.25 , respectively (Table 3 ). The $\%$ RSD for intraday reproducibility was 1.23 for BER and 1.7 for GZ; \% RSD for interday reproducibility was 0.58 for BER and 1.42 for GZ (Table 4 and 5).

Table 2. Repeatability data of peak area measurement for BER and GZ $(n=7)$

\begin{tabular}{llllll}
\hline BER & \multicolumn{5}{l}{ GZ } \\
\hline $\begin{array}{l}\text { Concentration } \\
\text { (ng/spot) }\end{array}$ & $\begin{array}{l}\text { Area } \\
\text { Mean } \pm \text { SD }\end{array}$ & \%RSD & $\begin{array}{l}\text { Concentration }(\mathbf{n g} / \\
\text { spot) }\end{array}$ & $\begin{array}{l}\text { Area } \\
\text { Mean } \pm \text { SD }\end{array}$ & \%RSD \\
\hline 300 & $3893.54 \pm 12.45$ & 0.32 & 600 & $7983.78 \pm 14.75$ & 0.18 \\
300 & $3785.82 \pm 8.54$ & 0.23 & 600 & $7028.23 \pm 18.21$ & 0.26 \\
300 & $3747.64 \pm 15.23$ & 0.41 & 600 & $7130.23 \pm 20.89$ & 0.29 \\
300 & $3652.29 \pm 18.11$ & 0.50 & 600 & $7160.81 \pm 18.19$ & 0.25 \\
300 & $3668.36 \pm 26.46$ & 0.72 & 600 & $7082.44 \pm 33.97$ & 0.48 \\
300 & $3587.25 \pm 5.99$ & 0.17 & 600 & $7248.06 \pm 24.99$ & 0.34 \\
300 & $3586.99 \pm 13.04$ & 0.36 & 600 & $7110.73 \pm 30.78$ & 0.43 \\
\hline
\end{tabular}


Table 3. Repeatability data of sample application for BER and GZ $(n=7)$

\begin{tabular}{cc}
\hline \multicolumn{3}{c}{ Peak Area } \\
\hline BER (300 ng/spot) & GZ (600 ng/spot) \\
\hline 3878.08 & 5963.04 \\
3889.84 & 5968.00 \\
3886.29 & 5974.66 \\
3891.33 & 5995.56 \\
3901.33 & 5997.99 \\
3890.86 & 5995.76 \\
3917.05 & 5991.45 \\
$3893.54 \pm 12.45$ & $5983.78 \pm 14.75$ \\
$0.32(\%$ RSD $)$ & 0.25 (\%RSD) \\
\hline
\end{tabular}

Table 4. Intraday reproducibility data for BER and GZ $(n=3)$

\begin{tabular}{llllll}
\hline BER & & & GZ & \\
\hline $\begin{array}{l}\text { Concentration } \\
(\text { ng/spot })\end{array}$ & $\begin{array}{l}\text { Peak Area } \\
\text { Mean } \pm \text { SD }\end{array}$ & \% RSD & $\begin{array}{l}\text { Concentration } \\
(\mathbf{n g} / \text { spot })\end{array}$ & $\begin{array}{l}\text { Peak Area } \\
\text { Mean } \pm \text { SD }\end{array}$ & \% RSD \\
\hline 200 & $2941.30 \pm 42.98$ & 1.46 & 400 & $5480.96 \pm 68.37$ & 1.25 \\
300 & $3917.28 \pm 28.39$ & 0.72 & 600 & $7547.41 \pm 105.39$ & 0.40 \\
400 & $4831.46 \pm 73.04$ & 1.51 & 800 & $9280.73 \pm 161.69$ & 1.74 \\
\hline
\end{tabular}

Table 5. Interday reproducibility data for BER and GZ $(n=3)$

\begin{tabular}{llllll}
\hline BER & & GZ & & & \\
\hline $\begin{array}{l}\text { Concentration } \\
(\text { ng/spot })\end{array}$ & $\begin{array}{l}\text { Peak Area } \\
\text { Mean } \pm \text { SD }\end{array}$ & \% RSD & $\begin{array}{l}\text { Concentration } \\
\text { (ng/spot) }\end{array}$ & $\begin{array}{l}\text { Peak Area } \\
\text { Mean } \pm \text { SD }\end{array}$ & \% RSD \\
\hline 200 & $2962.97 \pm 18.05$ & 0.61 & 400 & $5487.62 \pm 77.78$ & 1.42 \\
300 & $3899.02 \pm 15.65$ & 0.40 & 600 & $7547.41 \pm 105.39$ & 1.40 \\
400 & $4809.46 \pm 36.24$ & 0.75 & 800 & $9214.06 \pm 105.59$ & 1.15 \\
\hline
\end{tabular}

\subsection{LOD and $L O Q$}

LOD and LOQ value for BER was $35 \mathrm{ng} / \mathrm{spot}$ and $100 \mathrm{ng} /$ spot, respectively and GZ was $80 \mathrm{ng} / \mathrm{spot}$ and $200 \mathrm{ng} / \mathrm{spot}$, respectively.

\subsection{Accuracy}

Accuracy of the developed method was calculated by performing recovery studies. Proposed method was employed for estimation of amount of BER and GZ from pre analyzed sample solutions spiked at three different levels of standard. Mean \% recovery were found out to be $99.06-108.89 \%$ for BER and $93.79-99.11 \%$ for GZ (Table 6).

\subsection{Robustness}

The proposed HPTLC method was tested for robustness using PB design with 8 experiments. Seven HPTLC factors 
Table 6. Accuracy data for BER and GZ $(n=3)$

\begin{tabular}{lllll}
\hline Name of Drug & $\begin{array}{l}\text { Amount of standard spiked } \\
\text { (ng/spot) }\end{array}$ & $\begin{array}{l}\text { Average of amount recovered } \\
\text { (ng) }\end{array}$ & \% Recovery \pm SD & \%SD \\
\hline BER & 0 & 174.23 & & \\
& 60 & 237.77 & $108.90 \pm 52.65$ & 1.14 \\
& 120 & 326.69 & $102.52 \pm 80.34$ & 1.31 \\
& 180 & 369.08 & & 1.81 \\
GZ & & 399.95 & $99.11 \pm 84.49$ & 1.35 \\
& 0 & 475.74 & $93.79 \pm 106.32$ & 1.50 \\
& 80 & 562.74 & $95.35 \pm 72.28$ & 0.87 \\
\hline
\end{tabular}

Table 7. Factors and their levels for robustness testing of HPTLC method

\begin{tabular}{lllll}
\hline Factor Label & Factors & Levels & \\
\cline { 3 - 5 } & & $(-)$ & Nominal (0) & $(+)$ \\
\hline A & Change in volume of Toluene $(\mathrm{ml})$ & 4.8 & 5 & 5.2 \\
$\mathbf{B}$ & Change in volume of ACN $(\mathrm{ml})$ & 2.8 & 3 & 3.2 \\
$\mathbf{C}$ & Change in loading volume $(\mu \mathrm{l})$ & 1 & 5 & 10 \\
$\mathbf{D}$ & Change in saturation Time $(\mathrm{min})$. & 18 & 20 & 22 \\
$\mathbf{E}$ & Change in solvent run distance $(\mathrm{cm})$ & 7.5 & 8 & 8.5 \\
$\mathbf{F}$ & Change in detection wavelength $(\mathrm{nm})$ & 262 & 264 & 266 \\
$\mathbf{G}$ & Change in band length/slit dimension & $6 / 4$ & $8 / 6$ & $10 / 8$ \\
\hline
\end{tabular}

Table 8. Robustness data for BER and GZ

\begin{tabular}{|c|c|c|c|c|}
\hline \multirow{3}{*}{ Factor } & \multicolumn{4}{|c|}{ p - Value } \\
\hline & \multicolumn{2}{|l|}{ BER } & \multicolumn{2}{|l|}{ GZ } \\
\hline & $\mathbf{R f}$ & \% Recovery & $\mathbf{R f}$ & \% Recovery \\
\hline A & 0.2165 & 0.9608 & 0.5023 & 0.7538 \\
\hline B & 0.4134 & 0.5585 & 0.2441 & 0.8920 \\
\hline $\mathrm{C}$ & 0.0918 & 0.2064 & 0.6994 & 0.2523 \\
\hline $\mathrm{D}$ & 0.1482 & 0.4171 & 1.0000 & 0.3253 \\
\hline $\mathrm{E}$ & 0.9731 & 0.7140 & 0.4998 & 0.9276 \\
\hline $\mathrm{F}$ & 0.5785 & 0.8397 & 0.8152 & 0.9182 \\
\hline G & 0.2927 & 0.4219 & 0.6994 & 0.7538 \\
\hline
\end{tabular}

were analyzed (Table 7). The different levels for each factor were selected symmetrically around the nominal value of the corresponding factor. The limits of the factors studied were selected according to error ranges which would be typically encountered in an analytical laboratory. Pareto charts were used for the evaluation of robustness data for $\mathrm{R}_{f}$ value and $\%$ recovery (Fig.5). In all the situations, the $\%$ recovery and $\mathrm{R}_{f}$ value for BER and GZ were not significantly affected by factor changes (Table 8). Hence, the method was found to be robust.

\subsection{Analysis of marketed formulation containing BER and $G Z$}

The spots at $\mathrm{R}_{f}$ value 0.40 (for $\mathrm{BER}$ ) and $\mathrm{R}_{f} 0.68$ (for $\mathrm{GZ}$ ) were observed in the densitogram of the drug samples extracted from tablets. Amounts of BER and GZ were calculated using equation $\mathrm{y}=9.8151 \mathrm{x}+812.48$ for BER and $y=9.8016 x+1566.1$ for GZ. The $\%$ content was $0.088 \%$ for BER and $0.132 \%$ for GZ. 


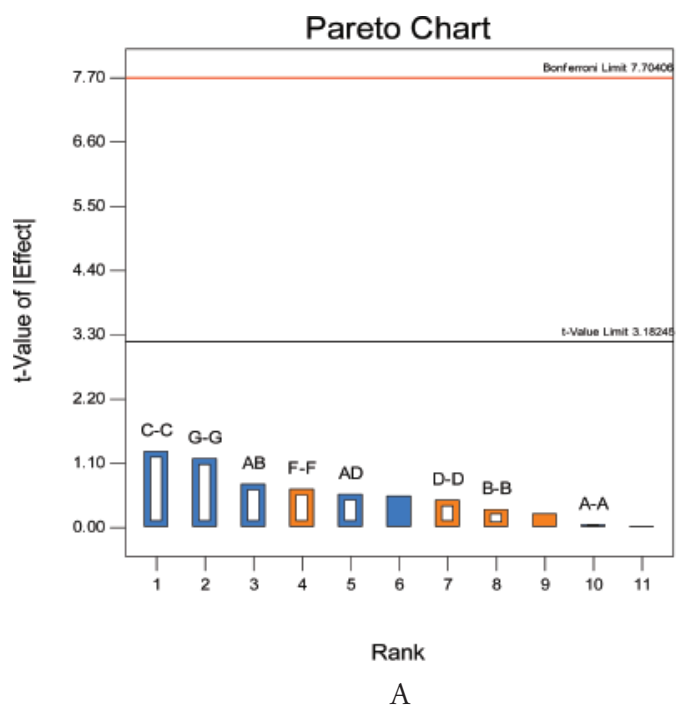

Figure 5. Pareto chart for (a) BER and (b) GZ

\section{Conclusion}

The proposed HPTLC method for simultaneous estimation of BER and GZ from marketed formulation was validated as per ICH Q2(R1) guideline [1]. The method was found to be linear in the range of $100-500 \mathrm{ng} / \mathrm{spot}$ for BER and 200-1000 ng/spot for GZ. Moreover, the method was found to be precise, accurate, robust and sensitive during validation performances. The method was successfully applied on commercially available Pilex tablet from Himalaya Herbals.

\section{References}

[1] ICH Q2(R1) guidelines, http://www.ich.org/ products/guidelines/quality/article/quality-guidelines. html.

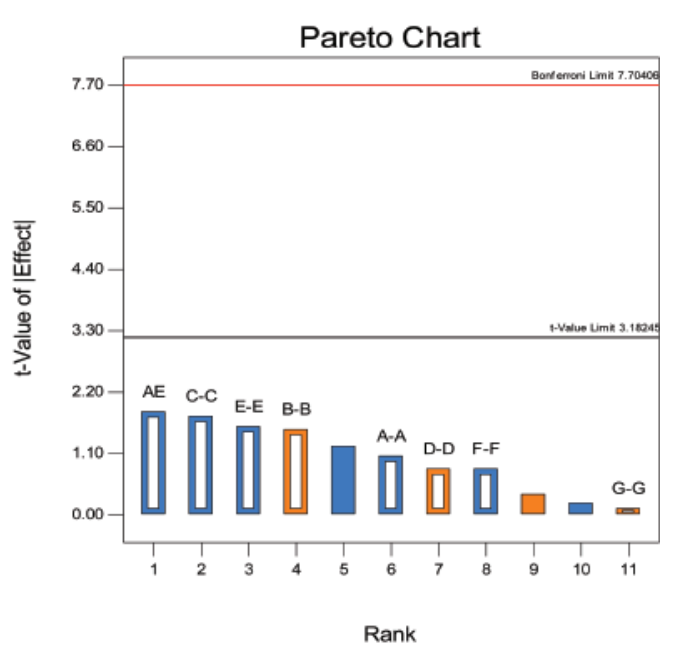

B

[2] Variya K, Parmar V. K. (2015). A Validated High Performance Thin-Layer Chromatographic Method for the quantitation of protodioscin in Trigonella foenum-graecum and its herbal formulation. Journal of Planar Chromatography. 6, 458-465. https://doi.org/10.1556/1006.2015.28.6.7

[3] Patel H. N., Parmar V. K., Patel B. (2014). Sensitive and Robust Methods for Simultaneous Determination of Beclomethasone Dipropionate and Formoterol Fumarate Dihydrate in Rotacaps. Journal of Chromatographic Science. 1-12. https://doi.org/10.1093/chromsci/bmt208

[4] Tarte P. S., Shedharkar G. R. (2014). Force Degradation Study of Berberine Chloride by Using Stability Indicating HPLC Method. International Journal of PharmTech Research. 6(5), 1490-1500. 